\title{
UN EXPERIMENTO TEMPRANO DE CAZA MODERNA DE BALLENAS EN MAGALLANES: EL VAPOR MAGALLANES DE LA BRAUN \& BLANCHARD Y EL CAPITÁN ANDRESEN
}

\author{
DANIEL QUIRÓZa \& MARCELO MAYORGA ${ }^{\mathrm{b}}$
}

\section{RESUMEN}

En este trabajo estudiamos un experimento ballenero proyectado por el capitán de origen noruego, Adolfo Andresen, llevado a cabo entre 1903 y 1904. Consistente en dos incursiones a lo largo del archipiélago patagónico-fueguino, destinadas a la caza de cetáceos y lobos marinos, experimento ballenero en que se utilizaría por primera vez equipamiento de la tradición ballenera moderna, en Magallanes, Chile y el hemisferio austral. Las fuentes utilizadas están dadas por 37 artículos publicados entre 1894 y 1904 en los diarios El Comercio y El Magallanes de Punta Arenas, y complementariamente, una serie de 12 cartas contenidas en el Archivo Mauricio Braun, información que permite caracterizar acabadamente el itinerario de la embarcación, los preparativos de la operación y los pormenores de las incursiones, aportando nuevos antecedentes para el mejor conocimiento de la cultura ballenera local y nacional.

PALABRAS CLAVE: caza de ballenas, tradición ballenera moderna, cañón arponero, Adolfo Andresen, Braun \& Blanchard, Punta Arenas.

AN EARLY EXPERIMENT OF MODERN HUNTING OF WHALES IN MAGALLANES: THE STEAMBOAT MAGALLANES OF THE BRAUN \& BLANCHARD AND CAPTAIN ANDRESEN

\section{ABSTRACT}

In this paper we study a whaling experiment that was projected by the Norwegian captain, Adolfo Andresen, developed between 1903 and 1904. Consisting of two incursions along the PatagonianFuegian archipelago, destined to the whaling and sealing, whaling experiment that used for the first time equipment of the modern whaling tradition, in Magallanes, Chile and the southern hemisphere. The sources used consist of a set of 37 texts published between 1894 and 1904 in the newspapers El Comercio and El Magallanes of Punta Arenas, and in addition, a series of 12 letters contained in the Mauricio Braun Archive, information that allows to fully characterize the itinerary of the ship, the

a Subdirección de Investigación, Servicio Nacional del Patrimonio Cultural, Moneda 650, 3er piso (Biblioteca Nacional), Santiago Chile. Proyecto FONDECYT 1170318. $\gg$ danielquiroz54@gmail.com.

b Universidad de Magallanes, Departamento de Educación y Humanidades, Avenida Bulnes 01855, Punta Arenas, Chile.

Proyecto FONDECYT 1170318. marcelo.mayorga@umag.cl. 
preparation of the whaling operation and the details of the incursions, providing new information for the better knowledge of the local and national whaling culture.

KEY WORDS: whaling, modern whaling tradition, harpoon cannon, Adolfo Andresen, Braun \& Blanchard, Punta Arenas.

\section{ANTECEDENTES}

El desarrollo económico del territorio magallánico ha estado ligado desde sus inicios a la caza de mamíferos marinos. La actividad fue iniciada hacia fines del siglo XVIII por marineros británicos y estadounidenses, los que interesados en las pieles de lobos finos (Arctocephalus australis y gazella) arribaron a las aguas del extremo austral americano en procura de los otrora abundantes otáridos, cuyas pieles eran exportadas hacia el puerto oriental de Cantón (China). De este modo, la caza de otáridos será la primera actividad económica desarrollada en el territorio magallánico (Martinic, 1987, p. 13).

Al promediar el siglo XIX, se produjo un dramático descenso en las poblaciones de pinnípedos, producto del devastador y febril paso de los marineros anglosajones, a tal punto, que la actividad prácticamente dejó de ser económicamente rentable. Años más tarde, a contar de 1860, con el desenvolvimiento de la colonia de Punta Arenas, la caza de lobos marinos volverá a adquirir importancia, para declinar durante la segunda década de la siguiente centuria (Martinic, 1973, p. 8-11), no sólo en lo tocante al área archipielágica de la Patagonia y Tierra del Fuego, ya que en las islas Falkland/Malvinas e insulas subantárticas, la importancia de la actividad decrece a contar de la segunda mitad del siglo XIX (Dickinson, 2007, p. 16).

Casi en simultaneidad, la fragata británica Amelie inauguraba la caza de cetáceos en las costas chilenas, cuando en 1792 captura el primer cachalote en la costa norte de Chile (Starbuck, 1876 , p. 96), siendo secundada posteriormente por cientos de embarcaciones balleneras de diferentes nacionalidades. A contar del siglo XIX, y con una marcada influencia del modelo de caza clásico yankee, empresarios nacionales organizan expediciones de caza de ballenas, teniendo como principal teatro de operaciones los puertos y caletas en torno a Talcahuano (Salvo, 2000, p. 65) y Valparaíso (Véliz, 1961, p. 30), a los que se sumaron a contar de la segunda mitad del siglo XIX, emprendimientos a menor escala, cuyo modelo extractivo operó bajo la modalidad tradicional, especialmente en las costas del golfo de Arauco (Quiroz, 2012, p. 1).

$\mathrm{Si}$ bien es cierto, las costas patagónicas fueron frecuentadas por los balleneros desde el inicio de las operaciones cinegéticas, la caza de cetáceos comenzaría recién a practicarse desde el puerto de Punta Arenas, al iniciar el siglo XX, esta vez bajo una tradición extractiva diferente a la que se venía practicando dentro del territorio nacional ${ }^{1}$. Nos referimos a la caza moderna de ballenas, caracterizada por el uso de un arpón explosivo lanzado desde un cañón dispuesto en la proa de un buque ballenero a vapor (Brown, 1976, p. 25). Es así, que la caza de mamíferos marinos, en su variante de caza de cetáceos, representa un hito más en la historia económica magallánica, por cuanto si la caza de otáridos fue la primera actividad económica en practicarse en esta zona del continente, la pesca de ballenas desarrollada desde Punta Arenas, será la primera que con equipamiento propio de la tradición ballenera moderna se llevó a cabo en aguas del hemisferio austral (Tønnesen \& Johnsen, 1982, p. 157).

En este trabajo se busca estudiar y profundizar en el "experimento ballenero" ideado y ejecutado por el capitán noruego Adolfo Andresen
Respecto del periodo que va desde 1843 hasta fines del siglo XIX, no existen estudios sistemáticos atingentes a la caza de ballenas que den cuenta de su eventual influencia y alcances en la vida y economía del Magallanes de este periodo (Quiroz, 2010, p. 39), aun cuando en los últimos años han ido apareciendo nuevos antecedentes que han permitido barruntar siquiera la verdadera significancia de las habituales recaladas de balleneros yankees en el puerto de Punta Arenas. Valgan como ejemplos las bitácoras de los balleneros estadounidenses Florence (diciembre de 1873), Wanderer (marzo de 1881) y Sarah W. Hunt (octubre de 1884), que en las fechas indicadas, recalan en el precitado puerto. 
y financiado por la firma naviera magallánica Braun \& Blanchard, ensayo cinegético que a la sazón sería el acicate para la inversión de capital en emprendimientos balleneros de mayor envergadura, los que perdurarian hasta 1916, fecha en que la Sociedad Ballenera de Magallanes es disuelta (Quiroz, 2011, p. 35).

Nos interesa analizar históricamente los inicios de la cultura ballenera en Magallanes a partir de la identificación de las tradiciones de caza presentes en este experimento que inaugura la caza moderna en el hemisferio austral, es decir, los influjos derivados de la industria ballenera noruega, de la caza pelágica de ballenas yankee, $y$, adicionalmente, de elementos propios de las operaciones de la caza de otáridos practicada por loberos angloestadounidenses, cuya presencia se explica por el carácter cosmopolita de la conformación social del Magallanes de fines del siglo XIX e inicios del XX.

\section{MATERIALES}

Para desarrollar este trabajo, hemos utilizado un conjunto de 37 artículos de prensa, publicados en los periódicos El Comercio y El Magallanes de la ciudad de Punta Arenas. Del total, catorce corresponden a informaciones referidas al devenir del vapor Magallanes, embarcación utilizada en este "experimento ballenero", contenidas en los números aparecidos entre 1894 y 1896. Las restantes veintitrés referencias corresponden a información relativa a los preparativos, pormenores y resultados de la expedición, y que abarcan el rango temporal que va desde 1903 a 1904. De igual modo, se tuvo acceso a doce documentos inéditos, consistentes en una serie de comunicaciones epistolares mantenidas fundamentalmente entre el empresario magallánico Mauricio Braun y su socio Juan Blanchard, donde este último informa con detalle a su socio respecto de la marcha del negocio de cabotaje y del reciente involucramiento en el rubro de la caza de ballenas.

En su conjunto, estos documentos constituyen un acervo documental que permite pormenorizar el origen, desarrollo y desenlace de esta apuesta experimental de caza de cetáceos en el extremo austral americano, contribuyendo a complementar y aclarar algunos aspectos anteriormente examinados por la historiografía abocada al tópico.

La información más abundante sobre este "experimento ballenero" se encuentra disponible en una serie de textos escritos por el historiador magallánico Mateo Martinic y publicados en la década de los 70. La información se puede agrupar en cuatro categorías, que denominamos: la nave, preparativos, expediciones y resultados.

La primera mención se presenta en 1973 en un trabajo sobre la caza de lobos y ballenas en Magallanes y la Antártica. En este texto Martinic no entrega antecedentes sobre la historia de la nave, sus características técnicas o su equipamiento. Sin embargo, en relación a los preparativos Martinic señala que "a mediados de 1903, cuando la empresa armadora magallánica Braun \& Blanchard adoptó la decisión de aparejar una de las naves de su flota mercantil para intentar la caza de ballenas en aguas del litoral pacífico de Magallanes, [aparece] asociado al proyecto un capitán noruego, Adolfo Andresen [... que] "había sido contratado [por Braun \& Blanchard] para comandar al Magallanes, vapor dedicado a tareas corrientes de fletamento que se estaba aparejando a fin de que pudiese iniciar la captura exploratoria de ballenas en la primavera de 1903" (1973, pp. 14-15).

Respecto de las expediciones Martinic indica que las campañas fueron dos: "Lista la nave zarpó el 18 de septiembre rumbo al Pacífico en busca de cetáceos, recorriendo en tal faena desde el estrecho de Nelson hasta el cabo de Hornos, con resultado infructuoso; retornó a Punta Arenas a fines de octubre sin haber capturado siquiera una sola ballena. El magro provecho de la expedición fue un botín de 1.300 cueros de lobo de un pelo [...] y 87 barriles de aceite del mismo animal. Pero este resultado, lejos de desanimar a Andresen, lo acicateó para llevar adelante la empresa y así tuvo autorización de la casa armadora para zarpar hacia Ancud en busca de tripulación avezada (5 de octubre de 1903). Contratados los nuevos tripulantes, el Magallanes reinició la exploración en una campaña de caza que lo llevó a recorrer toda la costa y canales entre el golfo de Penas y el cabo de Hornos, durante cuatro meses. En esta faena fue avistada la nave el 5 de noviembre de aquel 
año por el Lovart, otro vapor de la insignia de Braun \& Blanchard, a cuyo capitán participó Andresen que ya había cazado tres ballenas" (1973, p. 15).

La segunda referencia, algo más extensa, corresponde a un trabajo publicado en 1975 sobre el capitán noruego Adolfo Andresen y su participación en la caza de ballenas en Chile. Aquí, nos entrega varios datos sobre el buque, algunos históricos y otros técnicos. La nave "no era otra que el famoso Cabenda que había llevado al no menos nombrado explorador Henry M. Stanley en su segunda expedición africana". El buque fue "construido en 1872 en Liverpool [y] tenía originalmente 72 toneladas de registro neto"; adquirido en 1895 por Braun \& Blanchard, de Punta Arenas, quienes dispusieron en 1899 "su transformación en astilleros de Punta Arenas, aumentándose como consecuencia el tonelaje a 140 toneladas netas". Se le dio el nombre de Magallanes" (Martinic, 1975, p. 8).

En cuanto a los preparativos, señala que el capitán Andresen, una vez "radicado en Punta Arenas, pasó a ejercer la ruda actividad cazadora de animales marinos de piel fina en los desolados litorales occidentales del territorio magallánico, trabajos que combinó con ocasionalesoperaciones de salvataje de embarcaciones naufragadas. Tales tareas le permitieron explorar y conocer tanto la geografía marítima de la región como constatar la abundancia de lobos marinos y ballenas que había en los canales y en las aguas oceánicas, comprendiendo la importancia comercial que podía revestir la explotación en forma de tales recursos". Andresen "consideró [...] que tal actividad debía ser desarrollada con medios técnicos apropiados y [...] resolvió dirigirse a su pais, a Finmark, para imponerse sobre las características de la moderna caza ballenera mediante el empleo del cañón arponero recientemente inventado por su compatriota Svend Foyn, y aprender su utilización. Así lo hizo, en efecto, adquiriendo también uno de tales artefactos, retornando a Punta Arenas en el Otoño de 1903. Su preocupación le llevó a ponerse en contacto con el que sin duda era el empresario más clarividente de Magallanes, Mauricio Braun, armador y comerciante quien ya el año anterior había intentado la caza de pinnipedos en el litoral de las Shetland. Participó a éste el noruego la posibilidad de intentar la caza de ballenas en forma experimental y acogida la idea con entusiasmo por parte del armador, ambos se dieron a la tarea de realizarla. Para ello la casa Braun \& Blanchard de la que aquel era socio principal dispuso acondicionar para el objeto el vapor de su insignia Magallanes" (Martinic, 1975, pp. 7-8).

Martinic elabora luego un nuevo relato de las campañas del vapor Magallanes por los canales australes, no muy diferente de la primera: "Armado $y$ acondicionado para la caza el flamante y suigéneris ballenero, con Andresen al mando, zarpaba de Punta Arenas el 18 de Septiembre de 1903 en busca de sus primeras presas. Aunque la campaña lo llevó desde el Estrecho Nelson hasta el Cabo de Hornos, ella resultó infructuosa desde el punto de vista ballenero, trayendo únicamente y a manera de compensación una apreciable cantidad de cueros y aceite de lobos de un pelo. Lejos de desanimarse por el resultado Andresen decidió insistir en su empeño y fue así como obtuvo autorización para zarpar hasta Ancud para contratar alli una tripulación avezada para la faena cazadora, hecho lo cual el Magallanes emprendió una nueva campaña por el litoral desde el Golfo de Penas hasta el Cabo de Hornos. Para el 25 de Noviembre de aquel año Andresen había ya capturado tres ballenas, que según los historiadores noruegos de la caza pelágica, fueron las primeras obtenidas en el hemisferio austral mediante el uso del cañón arponero" (Martinic, 1975, pp. 8-9).

El tercer texto, un trabajo publicado en 1977 sobre la caza de cetáceos en Chile, entrega la misma información aunque en forma bastante más escueta. Insiste, en una breve nota, que el buque no era otro "que el antiguo Cabenda de la expedición de Stanley al Africa" (1977, p. 313). En cuanto a los preparativos y expediciones refiere que "en septiembre de 1903 la sociedad armadora Braun \& Blanchard aparejó como ballenero al vapor de su insignia Magallanes", lo "despachó en un primer e infructuoso recorrido del litoral exterior austral entre el estrecho Nelson (51 $45^{\prime}$ S) y el cabo de Hornos. Una segunda campaña desarrollada entre octubre y diciembre desde el golfo de Penas $\left(47^{\circ}\right.$ S) al cabo de Hornos resultó más provechosa. En 
aquella oportunidad se capturaron las primeras ballenas del hemisferio austral mediante el uso del cañón arponero inventado por Svend Foyn, artefacto que virtualmente revolucionó la caza de ballenas a partir del tercio final del siglo XIX" (Martinic, 1977, pp. 313-314).

En los textos posteriores, Martinic reitera la información ya entregada, agregando algunos datos nuevos. En sus libros sobre el antiguo Magallanes y sobre los "prohombres patagónicos" Mauricio Braun y José Menéndez, repite casi textual, con ligeros cambios de redacción, los párrafos del escrito de 1975 (1985, pp. 123-124; 2001, pp. 213-214). Lo mismo hace en un trabajo sobre los armadores de Punta Arenas (1995, pp. 137-138). Sin embargo, en el libro sobre Braun y Menéndez agrega un par de afirmaciones novedosas sobre la nave, al señalar que "en 1898 y luego que un siniestro lo afectara, el Cabenda fue renovado en un trabajo conjunto del astillero Bonacich Hnos. $y$ de la fundición de Wlodarowsky y Geysel, reincorporándose al servicio con el nombre de Magallanes" (2001, p. 125) y también, en una nota a pie de página, que el barco "se había hecho famoso años antes luego de servir de medio de transporte al explorador Henry Morton Stanley en su célebre exploración africana en busca de otro explorador, el Dr. David Livingstone" (2001, p. 156).

\section{LA NAVE: CABENDA/MAGALLANES}

En función de las categorías señaladas más arriba (La Nave, Preparativos, Expediciones y Resultados), nos ocuparemos de profundizar

2 Thomas Royden \& Sons, formada por los socios Thomas Royden y sus hijos Thomas B. y Joseph, era un importante astillero de Liverpool, que operó entre los años 1818 y 1893 [Royden, Ernest B., Thomas Royden \& Sons, Shipbuilders, Liverpool, 1818-1893. Liverpool: Binding Publishers, 1953; Wakefield, W. Heaton, A Brief History of Thos. Royden \& Sons. Liverpool: manuscrito, 1931].

3 Hatton \& Cookson, formada por los socios Edward Hatton y Thomas W. Cookson, era una empresa de Liverpool que comerciaba con aceite de palma en África Occidental desde 1838. En 1854 poseía 54 buques que operaban bajo su nombre y estaba entre los seis más grandes importadores de aceite de palma del Reino Unido [Lynn, Martin. Commerce and Economic Change in West Africa: The Palm Oil Trade in the Nineteenth Century. Cambridge: Cambridge y entregar nuevos antecedentes respecto de este proyecto/ensayo de caza de ballenas llevado a cabo en aguas australes, $y$ en determinados casos, a través de la revisión documental y análisis hermenéutico llevado a cabo, efectuar las debidas aclaraciones ante la presencia de inconsistencias en los datos. De igual modo, se recoge una serie de informaciones que contribuyen a complementar la información ya conocida (vide Martinic, 1975; Filippi, 1997; Quiroz \& Carreño, 2010) del precursor de la industria ballenera moderna en Chile, Adolfo Andresen, particularmente respecto de las actividades desarrolladas en los años previos a su involucramiento en esta actividad cinegética.

Corresponde referirnos a la embarcación utilizada por Andresen para concretar el "experimento ballenero" llevado a cabo entre septiembre de 1903 y febrero de 1904. Este vapor fue construido en 1871 por Thomas Royden $\&$ Sons $^{2}$ de Liverpool, para Hatton \& Cookson, comerciantes de Liverpool ${ }^{3}$, con un arqueo de 201 TG y 113 TN. Medía 130.6 pies de eslora, 20.1 pies de manga y 8.8 pies de puntal. Tenía un motor a vapor, compuesto, dos cilindros y $40 \mathrm{HP}$, fabricado por Fawcett, Preston \& Co, también de Liverpool $^{4}$.

Esta nave llegó a Punta Arenas el 20 de noviembre de $1894^{5}$, con el nombre de Cabenda, tras ser adquirida por la firma Braun \& Blanchard para labores de cabotaje, siendo matriculada con el mismo nombre en el Registro de la Marina Mercante Nacional de Chile (RMMN), con un arqueo de 197,36 TG y de 72,70 TN. Medía 39,74 $\mathrm{m}$ de eslora, 6,13 $\mathrm{m}$ de manga y 2,68 $\mathrm{m}$ de puntal ${ }^{6}$. Con el fin de ejemplificar el porte de

University Press, 2002].

4 La firma Fawcett, Preston Engineering, fue fundada en Liverpool en 1758, por George Perry. Su reputación internacional se construye en torno a la maquinaria para el procesamiento del azúcar y también por sus motores marinos. En 1935 se traslada a Bromborough y en 1947 llega a ser parte de Metal Industries Group [White, H., 1958. "Fossets", A record of two centuries of engineering, Bromborough: Fawcett, Preston \& Co. Ltd.].

5 El Magallanes, 2 de diciembre de 1894. Martinic (1975, p.8) señala que la firma Braun \& Blanchard había adquirido la embarcación el año 1895.

6 Lista oficial de los buques de la Marina Mercante Nacional de 1897. 156-168. Memoria del Ministerio de Marina presentada al Congreso Nacional en 1897. Santiago: Nacional. 
la nave, podía transportar hasta 100 bovinos en un viaje $e^{7}$.

Un diario de la época destacaba la llegada de esta embarcación, apuntando a que se venía a sumar al comercio de cabotaje ya realizado por los vapores Amadeo, Torino y Antonio Díaz, [y que] llegó a este puerto, procedente de Londres, el vapor Cabenda, comprado por la casa Braun y Blanchard para hacer el comercio de cabotaje del estrecho de Magallanes y las colonias de Santa Cruz y Gallegos. El Cabenda tiene 72 toneladas de registro y su andar medio es de 8 a 9 millas por hora. Salió de Londres el 8 de octubre y solo ha tocado en Las Palmas, Canarias, para tomar carbón ${ }^{8}$.

Esta información es corroborada por otra nota titulada "Cabenda", publicada dos semanas antes, donde se consigna que es este el nombre de otro vapor que hará en breve el comercio de cabotaje en el Estrecho. Pertenece a la casa de los Sres. Braun y Blanchard y fue adquirido en Londres. Desplaza 200 toneladas y su andar es de siete a ocho millas por hora. Según noticia cablegráfica enviada a la referida casa, el Cabenda salió de Las Palmas el 24 de octubre último y debe llegar a Punta Arenas en estos dias ${ }^{9}$.

Nueve años más tarde, otro periódico puntarenense, entrega información respecto de la trayectoria del Cabenda antes de ser destinado al cabotaje en las costas patagónicas, y al respecto señala que

El vapor Magallanes, además de los buenos servicios que ha prestado al comercio de cabotaje en estos mares, tiene en la historia de su navegación por otras comarcas, una nota muy interesante que muchos de nuestros lectores deben ignorar. Antes de venir a este Territorio, navegaba en las costas norteamericanas con el nombre de Kabenda, con que se hizo conocer aquí.
El Kabenda fue flotado por el gran diario norteamericano New York Herald, para enviar en él una expedición de periodistas $y$ fotógrafos, a fin que siguieran en su viaje al interior del África, al célebre explorador Mr. Stanley que, si mal no recordamos, fue en busca de su émulo el célebre Livingstone. El Kabenda siguió, pues, las aguas de Mr. Stanley por el río Congo hasta llegar a los grandes lagos Victoria y Nyanza, situados en el centro del Continente Negro. El New York Herald pudo de este modo, al regreso de la expedición ofrecer a sus lectores informaciones y notas gráficas más notables que ningún otro diario del mundo, sobre aquellos acontecimientos científicos de resonancia universal ${ }^{10}$.

La información contenida en El Comercio creemos responde a una confusión, por cuanto, y como veremos a continuación, Stanley efectivamente estuvo en la cubierta del Cabenda, pero en su segunda expedición al África (1874), cuyo objetivo era explorar el curso del río Congo, mas no en la efectuada en 1871.

Similar situación observamos en los textos de M. Martinic, quien entrega algunas afirmaciones sobre la relevancia del "famoso" Cabenda en las expediciones del "no menos célebre" explorador inglés Henry Morton Stanley: que lo habría conducido "en su segunda expedición africana" (Martinic, 1975, p.8) y/o que habría servido "de medio de transporte al explorador Henry $M$. Stanley en su célebre exploración africana en busca de otro explorador, el Dr. David Livingstone" (Martinic, 2001, p. 156).

Pero estas aseveraciones no son del todo exactas. La segunda simplemente no es posible. El encuentro de Stanley con el Dr. Livingstone ocurre a orillas del Lago Tanganyka el 10 de noviembre de 1871 (1872, p. 331 ${ }^{11}$ ) y el buque se termina de construir recién en diciembre de $1871^{12}$.

four months' residence with Dr. Livingstone. Londres: Sampson Low, Marston \& Co.

12 Liverpool Mercury (Liverpool), 14 de julio de 1891. Lloyd's Register of British and Foreign Shipping. Londres: Wyman \& Sons. 1874.
El Magallanes, 24 de noviembre de 1895.

El Magallanes, 2 de diciembre de 1894.

El Magallanes, 18 de noviembre de 1894.

El Comercio, 26 de marzo de 1903.

11 Stanley, H. M. 1872. How I found Livingstone: travels, adventures, and discoveries in Central Africa, including 
¿Qué tan "famoso" es el Cabenda, es decir, cuál es el rol específico que le cupo en la "segunda expedición africana" de Stanley?

Tenemos algunos datos que nos permiten establecer un vínculo documentado entre el "famoso" explorador y el buque. Una carta enviada por Stanley desde Boma al Daily Telegraph de Londres, fechada el 10 de agosto de 1877, termina con la siguiente frase: de aquí "llevaré a la expedición en vapor a Cabinda y de ahí a San Pablo de Luanda"13. Hemos revisado el relato de Stanley de su segundo viaje $e^{14}$, publicado en $1878^{15}$, y allí indica claramente que la expedición (o lo que queda de ella ${ }^{16}$ ) se traslada el 11 de agosto de 1877 en el vapor Kabinda, desde Boma a Cabinda ${ }^{17}$. Stanley y los otros miembros de su grupo expedicionario llegan a Cabinda en la mañana del 12 de agosto de 1877 (Stanley, 1878, pp. 466-468). El 20 de agosto viajan a Luanda, Angola, en la cañonera portuguesa Tamega; el 27 de septiembre se trasladan a Ciudad del Cabo en el buque de la marina británica HMS Industry y, en la misma nave, el 6 de noviembre, se dirigen a Zanzíbar (Stanley, 1878, pp. 473-483). Finalmente, Stanley regresa a Europa el 13 de diciembre de 1877 en el vapor Pachumba, de la British India Steam Navigation Co. Ltd.

Pero no es la única alusión al buque. El 9 de agosto de 1877, "el día 999 desde nuestra partida de Zanzíbar" (Stanley, 1878, p. 461), el explorador contempla el río Congo desde Boma:

Mirando desde la casa, mis ojos se fijaron en el río. Ese río odioso y asesino, ahora tan amplio, tan orgulloso

13 Daily Telegraph (Londres), 17 de septiembre de 1877.

14 La segunda expedición africana de Stanley, financiada por el New York Herald y el Daily Telegraph de Londres, fue realizada entre los años 1874 y 1877.

15 Stanley, H. M. 1890. Through the Dark Continent. Londres: Sampson Low, Marston, Searle \& Rivington Ltd. Hay una traducción de Mariano Blanch al español, que con el título El Continente Misterioso, fue publicado por capítulos en la revista Mundo Ilustrado, de Barcelona, por Espasa ediciones.

16 Después de casi mil días, el número de expedicionarios se había reducido drásticamente. De las 356 personas que iniciaron el viaje sólo 114 lograron llegar al Atlántico, siendo Stanley el único europeo en conseguirlo. Forbath, P. 2002. El río Congo. Descubrimiento, exploración y explotación del río más dramático de la tierra. México, y majestuosamente calmo, como si no me hubiera privado de un amigo y de muchas almas fieles, y como si nunca hubiese escuchado su rabia y su furia, imitando el trueno. ¡Qué río más hipócrita! Sin embargo, por debajo del embarcadero, un vapor estaba subiendo -es el Kabinda, con John Petherbridge, su capitán. ¡Cómo avanzaba la civilización sobre mí! ¡Ni siquiera un momento para acostarse $y$ descansar! Vigorosa, ansiosa, inquieta y agresiva, me asediaba reclamándome como cosa propia, sin permitirme el tiempo para echar una mirada retrospectiva a los horrores dejados atrás. Mientras todavía estaba abrumado por los pensamientos, aparecieron los miembros de la expedición, codeándose, atónitos, con los ojos desmesuradamente abiertos, para admirar la extraña "gran canoa de hierro", impulsada por el fuego en su río; había varios wanyamwezi, waganda y hombres de la costa oriental que no podian creer que hubiera algo más maravilloso que la Lady Alice ${ }^{18}$ (Stanley, 1878, p. 464) ${ }^{19}$.

El Cabenda, "la gran canoa de hierro", es un poético nombre para un buque misterioso. En resumen, existe una conexión significativa entre Stanley, su segunda expedición africana y el vapor Cabenda, pero dura apenas un par de días, no es de la magnitud que se sugiere en la literatura consultada.

Tornando a las actividades desarrolladas por el vapor Cabenda tras recalar en el puerto

FCE.

17 Boma se encuentra en la actual República Democrática del Congo y Cabinda es un enclave angoleño al norte del río Congo.

18 Lady Alice era el nombre de un bote de cuarenta pies de eslora, dividido en cinco secciones, que Stanley llevó consigo durante su expedición al río Congo. Cuando las secciones estaban unidas podía navegar en lagos y ríos; cuando se separaban, el bote podía ser transportado por tierra cientos de millas [Hochschild, A. 1999. King Leopold's Ghost: A Story of Greed, Terror and Heroism in Colonial Africa. Boston: Mariner Books].

19 Se consultó el Capítulo LXXII del libro, que aparece traducido en el Cuaderno 94 de Mundo Ilustrado (pp. 669675) publicado en 1881, pero la traducción que se presenta es nuestra. 
de Punta Arenas (hacia fines de 1894), y antes de ser transformado en un "sui-géneris ballenero", sus propietarios prontamente dispusieron de su uso para trabajos de cabotaje hacia la costa patagónica oriental, según se consigna en una breve comunicación de febrero de 1895, donde se informaba que el 12 de enero regresaba procedente de Río Gallegos y desde otros puertos del Estrecho, con un cargamento de 360 fardos de lana provenientes desde diversos establecimientos ganaderos ${ }^{20}$, los que prontamente serían embarcados hacia Inglaterra ${ }^{21}$. A mediados del mismo año, el Cabenda llevaba hacia Punta Arenas 270 fardos de lana desde San Julián y Santa Cruz, los que serían reembarcados en un vapor de la compañía naviera alemana Kosmos ${ }^{22}$, que tendría la misión de transportar la lana hacia los mercados europeos ${ }^{23}$. Frenética resultó ser la actividad del Cabenda durante su primer año en aguas australes, dado que tras llegar desde la anterior diligencia, es enviado a Puerto Stanley (isla Soledad/East Falkland), con un encargo de maderas de construcción y postes para $\operatorname{cerco}^{24}$, además de pasajeros ${ }^{25}$.

A modo de digresión, en junio de 1895, Juan Blanchard comentaba a su socio Braun la urgente necesidad de asegurar la embarcación (cuyo avalúo ascendía a la suma de £3,700), producto del que quizás, era el primero de varios siniestros que le tocó enfrentar a este vapor ${ }^{26}$. Valga este antecedente, con el fin de comparar su costo con el de un verdadero buque ballenero, los que sin considerar el equipamiento, costaban cerca de £5,000 (Tønnesen \& Johnsen, 1982, p. 39).

Si ya cargaba con algo de fama por su paso por África, "la gran canoa de hierro" adquiriría

20 Entre los lugares consignados en los documentos a los que se tuvo acceso, figuran Puerto Espora, San Julián, Puerto Santa Cruz, en la Provincia de Santa Cruz, Argentina; Puerto Stanley, en islas Falkland/Malvinas; en tanto que en territorio magallánico: Punta Delgada, Monte Dinero y Cabo Negro.

21 El Magallanes, 6 de febrero de 1895.

22 La Compañía Alemana de Vapores Kosmos, en 1869 se sumó al tráfico regular ultramarino a través del estrecho de Magallanes, comunicando Europa con los puertos americanos del Pacífico, sumándose a la Pacific Steam Navigation Company.

23 El Magallanes, 30 de junio de 1895a.

24 El archipiélago malvinense carece de madera para la connotación en las costas patagónicas, no sólo por sus eficientes trabajos en el comercio de cabotaje, sino que por un incidente jurisdiccional en el que se vio involucrado, cuyas implicancias hicieron eco en Buenos Aires. En sendas notas publicadas con los sugerentes títulos "¿Un casus bellis?"27 y "Nuestros vecinos están verdaderamente afectados de la monomanía del espionaje. En las costas del Sud. Un buque misterioso"28 (esta última publicada el 18 de marzo de 1895 en el diario El Tiempo de la capital argentina y transcrita en El Magallanes), y que reproducimos íntegras en el Anexo, se entregan abundantes detalles del entrevero acaecido en las cercanías de puerto Santa Cruz $\left(50^{\circ} 01^{\prime} 00^{\prime \prime} S-68^{\circ} 31^{\prime} 00^{\prime \prime}\right.$ ) $)$, localizado en la desembocadura del río homónimo.

La primera información, derivada de un oficio enviado por la firma Braun \& Blanchard a la Gobernación Marítima de Magallanes, refiere que el 4 de febrero la tripulación del Cabenda fue atacada con tiros de rifle por el vapor de transporte 1 de Mayo de bandera argentina, aparentemente ante la imposibilidad del Cabenda de responder al requerimiento de fondear que realizó el vapor argentino. Finaliza la nota con un sarcástico comentario del periodista, aludiendo probablemente a la figura del Gobernador de Santa Cruz, General Edelmiro Mayer (1892-1897).

El contexto de la época nos ayuda a entender lo recién señalado. En 1893 se firmaba un protocolo de acuerdo entre las repúblicas de Argentina y Chile, que venía a aclarar algunos aspectos técnicos del Tratado de 1881, y para el tema que nos ocupa, establecía que la línea demarcatoria entre ambos países sería la divisoria orohidrográfica, de modo que los

construcción, situación que permitió una temprana vinculación entre este archipiélago y el puerto de Punta Arenas (vide Martinic, 2009).

25 El Magallanes, 30 de junio de 1895a y 30 de junio de $1895 b$.

26 Carta de Juan Blanchard a Mauricio Braun, 10 de junio de 1895, Correspondencia Mauricio Braun [en adelante $\mathrm{CMB}$ ], Volumen 8,1, f. 21. Archivo Mauricio Braun [en adelante AMB],

27 El Magallanes, 24 de febrero de 1895. vide Anexo, Documento 1.

28 El Magallanes, 7 de abril de 1895. vide Anexo, Documento 2. 
territorios y aguas localizados al este, quedaban bajo soberanía argentina. Esta disposición era difícil de determinar en el distrito de Última Esperanza, de tal modo que el Gobernador de Magallanes, Manuel Señoret (1892-1896), decide otorgar algunas concesiones de tierras para uso pastoril en la mencionada área. Tal situación causó inquietud en los círculos gubernamentales santacruceños, derivando en reclamaciones diplomáticas (vide Martinic, 2006a, pp. 844847). De ahí es que habría surgido la también sarcástica nota aparecida en El Tiempo, donde el redactor de la nota se preguntaba ¿Han cesado los espionajes por tierra para dar principio por mar? El incidente quedaría superado, y el Cabenda proseguiría con sus viajes regulares a la costa patagónica argentina (de los que ya hemos mencionado algunos ejemplos), aun cuando, desde la tribuna de El Magallanes, confiaban en que durante el zarpe que efectuó a fines del mismo mes, no sean saludado[s] con salvas de balas de rifle por algún buque argentino de guerra ${ }^{29}$.

Entre 1896 y 1898, el Cabenda fue transformado en los astilleros de Carlos Bonacich \& $\mathrm{Cia}^{30}$ (ver Fig. 1), en Punta Arenas, quedando con 265,33 TG y 140,34 TN, y reinscrito en el RMMN con el $\mathrm{N}^{\circ} 644$ bajo el nombre de Magallanes ${ }^{31}$. Dicha transformación se vio forzada producto de un siniestro ocurrido al vapor al interior de la rada formada por la desembocadura del río Gallegos al iniciar el año 1896, frente a la costa de la estancia Killik Aike, en la ribera norte del río, al noroeste de la ciudad de Río Gallegos. En este lugar tocó en un banco y con la subida y bajada de las mareas principió a golpear, sufriendo la fractura de varias cuadernas, pero sin romperse el forro. Finalmente logran retornar a Punta Arenas, y tras

29 El Magallanes, 24 de febrero de 1895.

30 vide Chamorro, C. 1936. Bajo el cielo austral. Tomo I. Santiago: La Ilustración; Varas, C. 1996. Cien años del astillero varadero más austral del mundo, 1896-1996. Valparaíso: Imprenta Victoria.

31 Lista oficial de buques de la Marina Mercante Nacional, existentes el 31 de diciembre de 1901. Memoria del Ministerio de Marina presentada al Congreso Nacional en 1902. Santiago: Universo, 1902.

32 El Magallanes, 19 de enero de 1896. En junio del año anterior, ya había tenido otro incidente en bahía Inútil, frente a la costa de Tierra del Fuego, situación que habría motivado a Blanchard y Braun, el asegurar la embarcación la debida evaluación de los daños, cuya reparación significaba un costo de 15 a 20 mil pesos $^{32}$, el vapor quedó fuera de servicio por espacio de diez meses, hasta que sus propietarios decidieron invertir lo necesario, por cuanto el 27 de octubre de 1896 se daría comienzo a las labores de varadura del Cabenda en el astillero de los hermanos Bonacich (ver Fig. 2). Las reparaciones culminarían casi dos años después, labores que requirieron también la participación de la fundición Wlodarowsky y Geysel, procediéndose finalmente a su desvaradura en agosto de 1898, fecha a contar de la cual sería renombrado Magallanes (Varas, 1996, p. 18; Martinic, 2001, p.125).

Desde 1898 y por espacio de más de dos años, se pierde la pista de este vapor, con relación a los registros compulsados, y recién el 27 de septiembre de 1901 (Varas, 1996, pp. 3031) aparece mencionado, luego de ser sometido nuevamente a reparaciones, en el mismo astillero donde ingresara hacia fines de 1896. Casi al año y medio, reaparece nuevamente en faenas de cabotaje en Río Gallegos, específicamente en Punta Loyola ${ }^{33}$, zona no muy auspiciosa para el vapor (atendiendo al incidente de febrero de 1895 y el siniestro de enero de 1896), por cuanto mientras se aprestaba a despachar a tierra su cargamento consistente en postes y piquetes, un gran temporal del noroeste, que causó estragos en otras localidades como Puerto Espora, Punta Delgada e inclusive Punta Arenas, le provoca serias averías, quedando varado el vapor Magallanes, en la desembocadura del río Gallegos $^{34}$. Nuevamente la información deriva de puño y letra de Juan Blanchard, quien informaba a su socio Mauricio Braun que se hallaba en la localidad de Coronel.

(Correspondencia Mauricio Braun, 10 de junio de 1895, Volumen 8,1, f. 21. Archivo Mauricio Braun, Museo Regional de Magallanes [Punta Arenas]).

33 Esta es la denominación que recibe este puerto localizado a poco más de 30 kilómetros al este de Río Gallegos, en la actualidad es un terminal marítimo desde donde se despacha parte importante de la producción agrícola, ganadera y minera de las zonas aledañas (Roldán, 2004, p. 45).

34 Carta de Juan Blanchard a Mauricio Braun, 3 de abril de 1903, CMB, Volumen 14, f. 39. AMB, Museo Regional de Magallanes [Punta Arenas]. 


\section{AASTLLLELIR@}

\section{NAVAL A VAPOR DB}

BUHACIOH HEREANOS Y CIA CONSTRUCTORES NA YALBS

Se varan buques hasta de 1000 toneladas. Se construye toda clase de buques y se hacen reparaciones en fierro y madera, con o sin provision de materiales.

Punta Áronas- Estrocho do Magalianes

Fig. 1. Aviso publicitario del Astillero de Bonacic \& Cia. Fuente: Diario El Comercio, 1 de diciembre de 1903.

En este punto, aparece porvez primera asociado al otrora Cabenda, el capitán Adolfo Andresen, ya que era quien iba al mando del malogrado navío, toda vez que Blanchard manifestaba su molestia ante la decisión inconsulta del noruego, de varar el Magallanes en aquel lugar. Esta información es interesante, por cuanto resultaría ser, acaso el único dato concreto que da cuenta de las actividades previas de Andresen a las que se alude en los textos dedicados a la trayectoria del cazador noruego ${ }^{35}$, aquello específicamente en lo que a cabotaje se refiere, quedando por pesquisar información relativa a su involucramiento en la caza de animales pelíferos marinos.

Esto ocurrió el 23 de marzo de 1903, y los daños producidos fueron de tal envergadura, que hasta se evaluó si tras vararlo en Punta Arenas, convenía o no repararlo ${ }^{36}$.

Las evaluaciones de las averías que se practicaron en Punta Arenas debieron ser favorables, ya que en El Comercio se publicó una suerte de concurso para la reparación del buque, conminando a los interesados a requerir información referida a los datos y especificaciones de las reparaciones que [había] que hacer, además de informar que las propuestas se [abririan] ante los interesados que [concurriesen] el día 18 a las 2 p. $\mathrm{m}^{38}$.

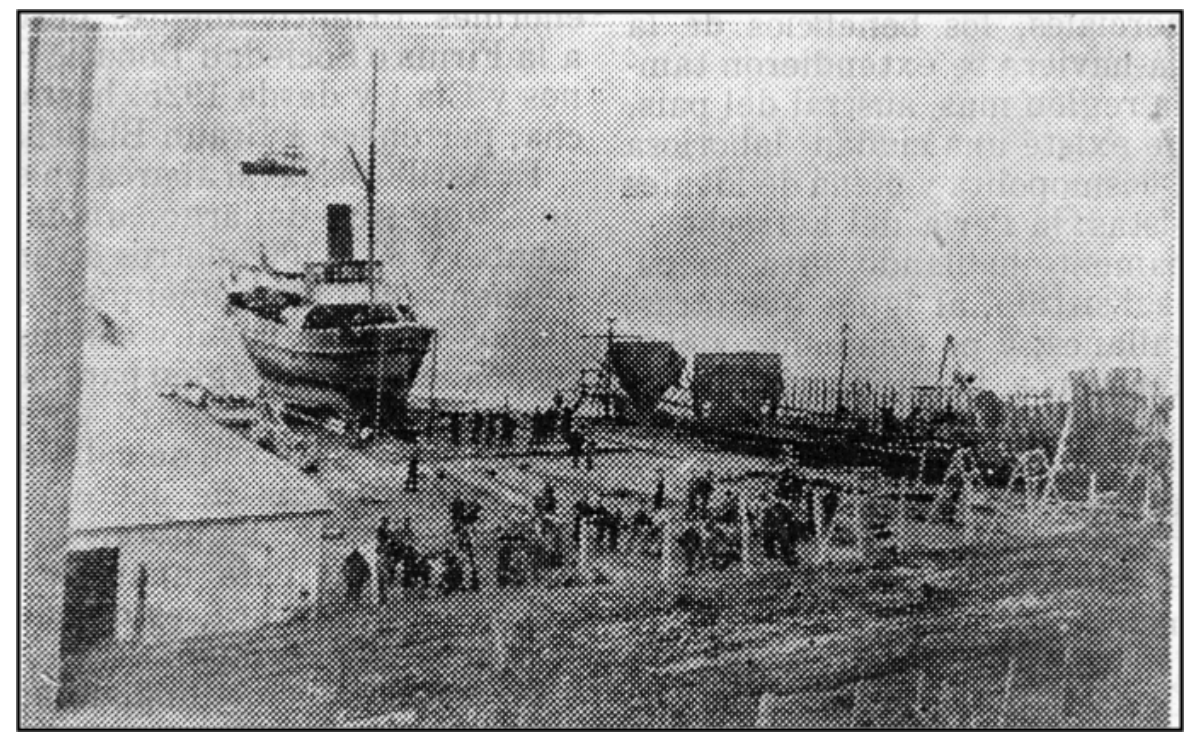

Fig. 2. A la derecha de la imagen, se muestra el casco del Cabenda en 1897, en plena faena de acondicionamiento.Fuente: Chamorro, C. (1936, p. 199) ${ }^{37}$

35 Nos referimos a los ya citados textos de Martinic, 1975; Tønnesen \& Johnsen 1982; Filippi, 1997; Quiroz \& Carreño, 2010.

36 Carta de Juan Blanchard a Mauricio Braun, 3 de abril de 1903, CMB, Volumen 14, f. 40. AMB, Museo Regional de Magallanes [Punta Arenas].
37 Se deja constancia, que a pesar de haber digitalizado la imagen en alta resolución, el original se presenta con escasa nitidez. Hemos decidido incluirla pues es el único registro fotográfico que se conoce de esta embarcación.

38 El Comercio, 16 de abril de 1903 
Hasta aquí llegarían, por el momento ${ }^{39}$, las tareas de cabotaje del Magallanes, faenas que desarrolló prácticamente desde su llegada al estrecho de Magallanes hacia fines de 1894, y que con largos periodos de obligada interrupción, pudo llevar a cabo hasta el accidentado mes de marzo de 1903. Todo parece indicar que sus propietarios buscaron dar un giro en el destino de la embarcación, ya que estando nuevamente en el astillero de los Bonacich, es que se decide aparejarlo para la caza de ballenas.

\section{PREPARATIVOS}

El año de 1903 resultará clave en el devenir del vapor Magallanes respecto de su vinculación con la inauguración de la industria ballenera local, además de representar un hecho señero a nivel nacional, al estrenarse en suelo magallánico equipamiento propio de la tradición ballenera moderna.

Según se indicó, en marzo de 1903 el Cabenda, ya capitaneado por Andresen, sufre importantes daños en la desembocadura del río Gallegos, y tras arribar a Punta Arenas, a inicios del mes de abril ${ }^{40}$, es ingresado, como en ocasiones anteriores, al astillero Bonacich.

Será este el momento elegido por Adolfo Andresen para convencer a sus empleadores en involucrarse activamente en la caza de cetáceos, confiado en la experiencia adquirida desde su llegada a Punta Arenas en 1894, espacio de tiempo donde además del tráfico marítimo, se dedicó a la caza de animales de piel fina en los canales patagónicos, y donde pudo observar la presencia de cetáceos en aguas interiores y exteriores [... cavilando] acerca de la posibilidad de intentar su captura mediante la tecnología hacía poco inventada por su compatriota Svend Foyn, esto es, con el empleo del cañón arponero (Martinic, 2001, p. 213).

Al parecer su fama de avezado marinero

39 Tras regresar de la segunda campaña hacia mediados de febrero de 1904, se reporta que el vapor saldría hacia Puerto Harberton, Ushuaia, Picton y otros puertos del sur, para llevar personas y carga, el día 8 de abril (El Comercio, 6 de abril de 1904).

40 El Comercio, 3 de abril de 1903.

41 El Comercio, 20 de junio de 1903. caló hondo en Mauricio Braun, quien inicialmente opinaba respecto de esta industria que la caza de ballena había fructificado en otros ilusos [...], agregando seguidamente que su interés se acrecentó desde que [...escuchó] los relatos del capitán Adolfo Andresen, [...] ya que apalabrado por él (Andresen) y semiconvencido, yo vacilaba antes de comprometerme (Braun, 1985, p. 207).

De aquel modo, en junio de 1903, en una nota titulada "La Pesca de ballenas", la prensa local, específicamente El Comercio, se adelantaba en informar: Se dice que una acreditada firma de esta ciudad, piensa dedicarse este año a la pesca de ballenas. Sabido es que en estas regiones hay épocas en que abundan esos cetáceos, pudiendo dar lugar su pesca a un pingüe negocio para el que la emprenda ${ }^{41}$. Siete días después, el mismo semanario, esta vez bajo el rótulo de "Pesca de ballena y focas", publica que "la firma de Braun i Blanchard ha solicitado de la Comandancia el permiso correspondiente para la pesca de ballenas i focas" 42 .

Transcurridos virtualmente cinco meses desde su varadura en el astillero Bonacich, a fines de agosto se lleva a cabo la botadura del que a contar de entonces pasará a llamarse Magallanes ${ }^{43}$, cuya capitanía a esas alturas ya tenía nombre y apellido, a la luz de lo que consigna la prensa local, que como es sabido, este vapor ha sido arreglado expresamente para dedicarlo a la pesca de ballenas en el estrecho $i$ estará al mando del capitán señor Andersen [sic] ${ }^{44}$.

A la luz de las fuentes compulsadas, no existen antecedentes que permiten precisar la fecha del viaje de Andresen a Noruega. Los historiadores noruegos Tønnesen y Johnsen refieren que el capitán ballenero se dirigió a Finmark, con el fin de adquirir habilidad como artillero, aprovechando de participar en operaciones de caza de ballenas (1982, p. 157). Aquello debió ocurrir entre inicios de abril de 1903, posterior a la llegada de Andresen

42 El Comercio, 27 de junio de 1903.

43 Lista oficial de buques de la Marina Mercante Nacional, existentes el 31 de diciembre de 1901. Memoria del Ministerio de Marina presentada al Congreso Nacional en 1902. Santiago: Universo, 1902.

44 El Comercio, 20 de agosto de 1903. 
de su malograda incursión en las cercanías de Punta Loyola a bordo del Cabenda.

En cuanto al regreso, habría ocurrido con seguridad antes de septiembre $e^{45}$, teniendo en cuenta una misiva escrita (en idioma inglés) desde Punta Arenas por el propio Andresen, con fecha 4 de septiembre, cuyo receptor era Mauricio Braun. La misiva sirve incluso como medio de verificación de la realización del viaje a Noruega, particularmente cuando le refiere a Braun: [...] como he estado en casa pero muy poco, nunca tuve la oportunidad de hacer esto ${ }^{46}$ (Documento 3, Anexo). Lo anterior, aludiendo a un trámite que necesitaba realizar, de modo de cumplir con las disposiciones legales que le permitiera capitanear una embarcación en Chile, a la luz de un reciente cambio legal al que alude el noruego en la misiva.

Más allá de la fecha precisa del retorno de Andresen de su viaje a Finmark, el objetivo inmediato era informarse de los avances en la industria ballenera moderna, consistentes en la incorporación a las proas de los buques de un cañón arponero, artefacto de reciente creación por parte del también noruego Svend Foyn (Martinic, 1975, p. 8), uno de cuyos ejemplares fue encargado por el capitán Andresen, además del equipamiento complementario que permitiera llevar a cabo la faena cinegética bajo esta recientemente practicada modalidad de caza de cetáceos, instrumental que finalmente llega a Punta Arenas los primeros días de septiembre de 1903.

Interesantes detalles respecto de los preparativos que requirió esta sui géneris e inédita operación ballenera los consigna El Comercio, en una nota algo más extensa, publicada bajo el rótulo Vapor Magallanes: Lanzado al agua del varadero de Bonacich Hnos., se ocupa actualmente este vapor en hacer provisiones para el viaje que próximamente emprenderá a los canales, para dedicarse a la pesca de ballenas, lobos, etc. Instalados en sus bodegas dos fondos destinados a beneficiar el valioso cetáceo i preparada la cubierta para hacer la faena, falta solamente

45 Martinic refiere genéricamente que Andresen habría retornado en el otoño de 1903 (1975, p. 8; 2001, p. 213).

46 Carta de Adolfo Andresen a Mauricio Braun, 4 de septiembre de 1903, CMB, Volumen 15, f. 19. AMB, Museo Regional de Magallanes [Punta Arenas].

47 El Comercio, 27 de agosto de 1903. para su completo equipo de pesca, el cañón lanza-arpones que debe llegar en estos días de Noruega y que será colocado a proa del barco. Ya tendremos oportunidad de ocuparnos nuevamente de este vapor, cuando se encuentre completamente listo para zarpar a la pesca ${ }^{47}$. Complementa esta información El Magallanes, donde se informa que este vapor saldrá para la pesca de ballenas en unos diez días más. Se ha telegrafiado a Valparaíso pidiendo se remita por el primer vapor el eje para la hélice, que es lo único que falta para quedar completamente listo para su viaje. El costo del cañón arponero, con todos los demás accesorios que completan el armamento para dicha pesca, ha tenido un costo de 1.000 libras esterlinas ${ }^{48}$. Finalmente el cañón al que aluden ambos semanarios, llegaría a la capital magallánica a bordo del Servia (vapor de la naviera alemana Kosmos), donde además se trajo la munición respectiva, arpones i demás accesorios destinados al equipo para la pesca de ballenas ${ }^{49}$.

Conviene aquí detenerse en precisar algunos aspectos recogidos en sendas notas periodísticas. El viaje además de estar destinado a la pesca de cetáceos, tenía como objetivo secundario cazar lobos marinos, situación que estuvo desde un principio planificada ante la eventual imposibilidad de dar con alguna ballena, lo que como se verá, efectivamente ocurrió. De hecho, en carta de Blanchard a su socio Mauricio Braun, le informa que Andresen se compromete a traer el buque cargado de aceite de lobos sino encuentra otra $\cos a^{50}$.

El calificativo sui géneris responde a que esta operación utilizará por vez primera en Chile equipamiento moderno para cazar ballenas, pero no necesariamente basada en la tradición moderna inaugurada por los noruegos, vale decir, aquella caracterizada en que una vez que la ballena era arponeada, sus carcasas son transportadas a plantas costeras, donde finalmente eran procesadas. En vez de trasladar

48 El vapor nacional 'Magallanes': El Magallanes, 3 de septiembre de 1903.

49 El Comercio, 3 de septiembre de 1903.

50 Carta de Juan Blanchard a Mauricio Braun, 4 de septiembre de 1903, CMB, Volumen 15, f. 105. AMB, Museo Regional de Magallanes [Punta Arenas]. 
las presas a la costa para su posterior beneficio, se planificó procesar los mamíferos marinos en la cubierta del improvisado ballenero, a la usanza de la tradición clásica yankee ${ }^{51}$. Para esto, el equipamiento que se habría utilizado para la obtención del aceite, serían los dos fondos u ollas de los que da cuenta El Comercio del 27 de agosto. Estos fondos debieron ser similares a los utilizados en la caza pelágica o tradición clásica yankee, donde se disponían en la cubierta de los veleros, apoyados en una estructura de ladrillos, artefactos que en inglés eran denominados try-works, utilizados también en los veleros dedicados a la caza de lobos marinos, industria donde era usual que las ollas pudiesen transportarse a la costa para realizar el cocimiento de la grasa de los otáridos (vide Headland, 1992, p. 53; Davis et al. 1997, p. 36). Conviene señalar este último antecedente, atendiendo a los acontecimientos que se tratarán en el siguiente acápite.

Volviendo a lo referido a los preparativos de la expedición, Blanchard aporta una serie de aspectos que da cuenta de lo planificado de la operación, cuyo fecha original de zarpe se esperaba que ocurriese el día 8 de septiembre, pero debido al retraso en la llegada del crank shaft o eje de la hélice del vapor, no se pudo salir en la fecha programada originalmente. La ansiada pieza llegaría el 13 de septiembre, situación que es informada en El Magallanes: En el "California" llegaron las piezas que faltaban para el vapor "Magallanes" de manera que ya podrá salir para la pesca de ballena, una vez que queden colocadas dichas piezas. Comenta el socio de Braun, que no ha sido muy facil [sic] conseguir la gente para la pesca, pero enfin [sic] se ha contratado el personal en las condiciones que se habian [sic] acordado, garantizando sin embargo de que el personal

51 Esta forma de cazar y procesar cetáceos, comienza en la segunda mitad del siglo XVIII desde las costas de Nueva Inglaterra. La caza se realizaba con veleros que llevaban a bordo botes balleneros. Cuando se divisaba una ballena, los botes eran bajados de los buques. Desde el bote, el arponero lanzaba, a muy corta distancia, uno o más arpones contra la ballena. Herida, ésta remolcaba los botes balleneros en su huida. Cuando se cansaba, el timonel la mataba con una lanza que hundía en el cuerpo de la ballena, la cual era llevada a un costado del velero, donde era descuartizada; la ganara un sueldo minimum [sic] de \$70-al mes sin que tengan derecho a sobre tiempo ${ }^{52}$. Igualmente se tenía proyectada la fecha de regreso de la primera campaña ballenera, el 20 de octubre, además de estimar el zarpe de la segunda incursión para noviembre. Respecto de Andresen, comentaba que está el hombre encaprichado en salir lo mas pronto posible $i$ [sic] lo tengo todos los días para preguntar por el crank shaft, comentario que daba cuenta del nerviosismo del noruego, ya que de acuerdo a su experiencia, la temporada de caza de ballena iniciaba el 1 de septiembre, sumado a que el Magallanes a pesar de haber sido botado el 25 de agosto, el mal clima y el retraso en la llegada del crank shaft, impedían la concreción del zarpe $^{53}$.

Contratiempos de por medio, finalmente el Magallanes zarparía durante un doblemente histórico 18 de septiembre de 1903, lo que quedaría bien reflejado en el acertado comentario incluido en El Magallanes, respecto de la trascendencia del hecho: [...] No está demás hacer un poco de historia sobre esta pesca en los mares del sur de la República, que servirán al mismo tiempo de estímulo a la Casa de los señores Braun y Blanchard, que son los primeros que en Magallanes, no sabemos si en Chile, han iniciado esta empresa con los más modernos elementos ${ }^{54}$.

\section{EXPEDICIONES}

En este apartado, nos referiremos a los pormenores de las dos expediciones cinegéticas que implicó este histórico experimento ballenero. El primero de los zarpes transcurrió entre el 18 de septiembre y el 24 de octubre de 1903, en tanto que la segunda campaña, duró desde el 5 de noviembre hasta el 17 de febrero de 1904.

grasa era retirada y subida a bordo mediante poleas. En el velero era transformada en aceite usando hornos instalados a bordo (Quiroz \& Carreño, 2017, p. 37).

52 Carta de Juan Blanchard a Mauricio Braun, 4 de septiembre de 1903, CMB, Volumen 15, f. 105. AMB, Museo Regional de Magallanes [Punta Arenas].

53 Carta de Adolfo Andresen a Mauricio Braun, 4 de septiembre de 1903, CMB, Volumen 15, f. 19. AMB, Museo Regional de Magallanes [Punta Arenas].

54 El Magallanes, 22 de septiembre de 1903. 
Martinic refiere que la primera incursión del ballenero Magallanes, abarcó desde el estrecho Nelson ${ }^{55}$ (Fig. 3) hasta el Cabo de Hornos (1975, p. 8). El momento en que zarpó aquel 18 de septiembre es descripto en El Comercio, y caracteriza adecuadamente cómo lucía su mortífero equipamiento:

[...] llamaba la atención en su equipo el mortero para lanzar arpones que se le colocó en la proa, que tiene metro $y$ medio de largo con un calibre de 3 pulgadas 1/16. Es de hierro forjado y se carga por la boca. Cada disparo se hace con 500 gramos de pólvora, que lanza el arpón a una distancia considerable. El arpón tiene una espiga con punta de acero, y al ser colocado en el arma a manera de proyectil, sobresale un poco fuera de la boca del mortero. De más está decir que el arpón está atado a un fuerte cabo, con el cual queda sujeto el cetáceo en caso de un golpe certero. El capitán del nuevo ballenero, señor Anderson [sic] iba halagado con la perspectiva de una provechosa excursión ${ }^{56}$.

En carta datada el 2 de octubre de 1903, Blanchard informa que el Magallanes fue avistado sin novedad a 60 millas al norte del Cabo Pilar ${ }^{57}$ (Fig. 3), es decir, en plena boca occidental del estrecho de Magallanes. El 24 de octubre retornaba el vapor con un cargamento de $1300^{58}$ cueros de lobos de un pelo y varias decenas de barriles de aceite extraída de aquellos parajes, campaña en la que encontró una sola ballena chica, a la cual por vía de ensayo se le disparó el arpón sin poder fijarla ${ }^{59}$.

55 Localizado en las coordenadas $50^{\circ} 01^{\prime} 00^{\prime \prime} \mathrm{S}-68^{\circ} 31^{\prime} 00^{\prime \prime} \mathrm{O}$, prácticamente en línea recta hacia el oeste de la ciudad de Puerto Natales.

56 El Comercio, 22 de septiembre de 1903.

57 Carta de Juan Blanchard a Mauricio Braun, 2 de octubre de 1903, CMB, Volumen 15, f. 85. AMB, Museo Regional de Magallanes [Punta Arenas].

58 Nos quedamos con la información que proporciona Martinic (1973), que coincide con la cifra informada en El Comercio, del 27 de octubre de 1903. Respecto de la cantidad de barriles de aceite de lobo, resulta complejo señalar una cifra: Martinic (1973), habla de 87 barriles; El
De acuerdo a Andresen, el viaje [...] no ha correspondido [...aquella] vez a sus esperanzas, El tiempo no le fue favorable i no encontró ninguna ballena, por lo que hubo de dedicarse solo a la pesca de lobos [...] Próximamente volverá a hacer otra campaña ${ }^{60}$. Aquello a lo que se comprometía a realizar en caso de no encontrar "otras cosas", resultó ser una profecía autocumplida.

La primera campaña a pesar de no haber sido exitosa, dado que no se cazó ningún cetáceo, sirve para demostrar positivamente que Andresen conocía del rubro de la caza de animales pelíferos, en este caso, lobos de un pelo ${ }^{61}$, ya que logran cazar 1.300 de estos otáridos (en la segunda campaña obtienen 2.400), para cuya obtención se requería de la ejecución de una serie de maniobras, tales como, acercarse en dirección barlovento a las loberías para no causar la estampida de los animales, organización a la hora de dar cuenta de los pinnípedos, diestro manejo del cuchillo con el fin de cuerear rápidamente los animales, etc., y por cierto, se requería de un alto nivel de conocimiento de la geografía de los intrincados canales patagónicos, que permitiera, entre otras cosas, dar con un lugar adecuado donde disponer los fondos que servían para hervir la grasa y obtener el aceite. Este punto es otro elemento que hace que estas campañas cinegéticas respondan a las características de un experimento, ya que por un lado tenemos la idea de probar un cañón arponero en un improvisado vapor (emulando la tradición ballenera moderna), con elementos de la tradición clásica yankee, y de otro lado, se dispone equipamiento que permitía beneficiar cetáceos y pinnípedos, de forma tal, que en vez de las características goletas loberas, aquí se usó un vapor para cazar lobos marinos.

Antes de iniciar la segunda incursión, que abarcaría un área geográfica de mayor amplitud

Comercio (26 de octubre de 1903) registra 80 barriles; El Magallanes (27 de octubre de 1903) eleva la cifra a 200; y finalmente, en información recogida en El Comercio (12 de noviembre de 1903) se indica que en el vapor Sallust se embarcaron 97 barriles de aceite de lobo que habían sido beneficiados a bordo del Magallanes, para ser destinados a Valparaíso.

59 El Comercio, 26 de octubre de 1903.

60 El Comercio, 27 de octubre de 1903.

61 También denominados lobos comunes, cuyo nombre científico es Otaria flavescens. 


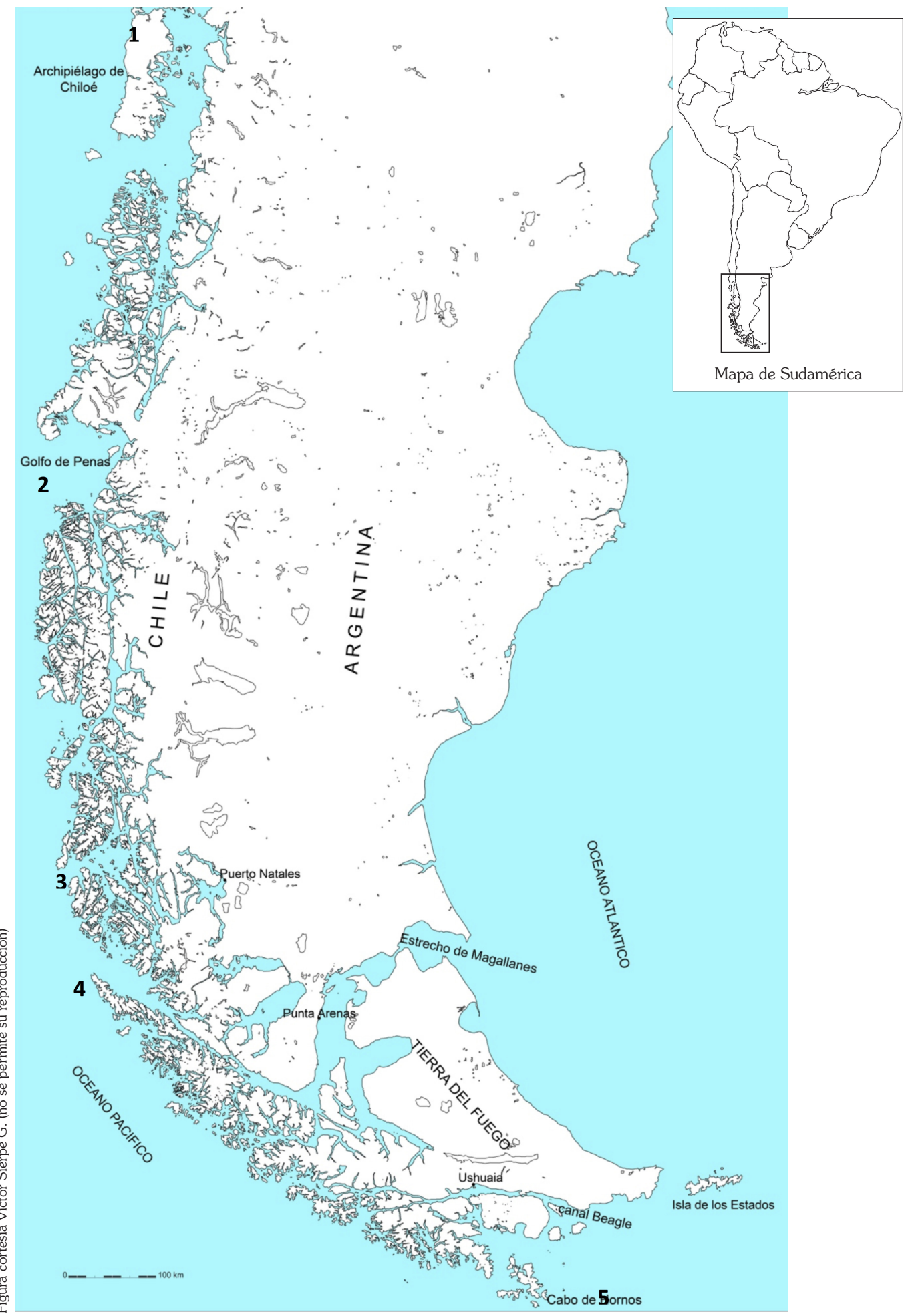

Fig. 3. Localización general de las áreas mencionadas en el recorrido de las expediciones del Magallanes: 1 Ancud, 2 Golfo de Penas, 3 Estrecho Nelson, 4 Cabo Pilar, 5 Cabo de Hornos. 
que la primera campaña, dado que incluyó desde el golfo de Penas (Fig. 3) hasta el cabo de Hornos (Martinic, 1973, p. 15), Andresen y asociados debían sortear el problema de la escasez de brazos. Aquella problemática ya era analizada por Blanchard, por cuanto pensaba en acudir al puerto chiloense de Ancud a requerir el concurso de 30 hombres $^{62}$, dado que se pensaba iniciar el crucero ballenero durante el mes de noviembre. Un día antes de que zarparan en la segunda y última campaña que abarcó este experimento de caza de mamíferos marinos, El Magallanes informaba que:

Este vapor anunció zarpar hoy para Ancud, con el objeto de buscar gente apropiada para el servicio de él y de la caza de ballenas. Aquí no se ha encontrado gente apta y que reúna las condiciones necesarias para el objeto a que se ha destinado el vapor. Sabemos que actualmente le falta gente para el viaje a Chiloé, por cuya causa es probable postergue su viaje ${ }^{63}$.

Las causas de la escasez de personal son registradas en una nota subtitulada sarcásticamente "The maiden whaler", que podría traducirse como "El ballenero virgen", dado que no había podido aún cazar ninguna ballena. Al respecto se refería que

Antes de regresar pasará posiblemente hasta Ancud a contratar algunos trabajadores aptos para las faenas de carga y descarga en la bahía, las que hoy tropiezan con dificultades por falta de brazos. Esta escasez se explica fácilmente en esta época del año, pues es la destinada en el campo a la faena de marcar animales, en la que se emplea bastante gente. La escasez es también debida en mucha parte, a la implantación de algunas industrias, nuevas empresas ganaderas, $i$ otras manifestaciones de progreso industrial

62 Carta de Juan Blanchard a Mauricio Braun, 4 de septiembre de 1903, CMB, Volumen 15, f. 106. AMB, Museo Regional de Magallanes [Punta Arenas].

63 El Magallanes, 5 de noviembre de 1903. nacidas de la fijación de la propiedad rural ${ }^{64}$.

Con el fin de explicar el contexto esbozado por El Comercio, valga mencionar que para la época en comento, la ganadería ovina experimentaba un espectacular auge, verbigracia, de las 300 primeras cabezas de ganado internadas en la isla Isabel en 1876 con fines de explotación ganadera, para 1900 se contaba con una dotación de 1.089 .000 cabezas, y para 1906 , la cifra alcanzaba la cifra 1.874 .650 ejemplares (Martinic, 2001). Hacia 1904, surgiría el establecimiento industrial consistente en el Frigorífico de Río Seco, donde se beneficiaba prácticamente toda la producción de la Patagonia, hasta antes de la inauguración de los demás frigoríficos, tanto en Magallanes, como posteriormente en la trasandina provincia de Santa Cruz (Contardi, 1920, p. 38). Este periodo está marcado también por el auge de la industria aurífera, que entre 1903 y 1908 vivió una suerte de fiebre, llegándose a registrar más de 30 sociedades constituidas con estos fines (Martinic, 2006b, p. 897).

Previo a la segunda campaña, el día 27 de octubre Andresen intenta un nuevo zarpe, aparentemente ante la noticia del avistamiento de cetáceos en aguas cercanas, retornando el mismo día ${ }^{65}$. Nueve días después, emprendería rumbo hacia el norte, con destino a Ancud, dando inicio a la campaña final del "experimento ballenero" capitaneado por Andresen, campaña que habría de extenderse tentativamente por seis meses, o mejor dicho, durará tanto como dure la provisión de viveres que llevan a bordo ${ }^{66}$.

En definitiva, el crucero se extendió por un lapso superior a los tres meses, espacio de tiempo donde el "maiden whaler" pudo obtener dos mil cuatrocientos cueros de lobo de un pelo, 300 barriles de aceite de ballena y de lobo y todo lo que se ha podido utilizar de 4 ballenas que ha pescado67. En una nota informativa de diciembre del año anterior, se informaba que el vapor Lovart se había reunido con el Magallanes, comunicándole que en Chiloé había tomado la gente que necesitaba y que en esos mares habian

64 El Comercio, 29 de octubre de 1903.

65 El Magallanes, 28 de octubre de 1903.

66 El Magallanes, 5 de diciembre de 1903

67 El Comercio, 18 de febrero de 1804. 
cazado tres ballenas, las que fueron beneficiadas, calculando su producido en $£ 1.000$ cada una ${ }^{68}$. Tønnesen y Johnsen aportan el dato de que habría sido en vísperas de Año Nuevo, el momento en que el Magallanes habría cazado su primera ballena con el cañón arponero adquirido poco tiempo atrás por el propio capitán Andresen en su tierra natal.

\section{RESULTADOS}

Al evaluar el resultado de ambas campañas, puede quedar la impresión de que el proyecto ballenero resultó ser un fracaso. Sin embargo, considerando la información ya conocida, junto con los nuevos antecedentes a los que se pudo acceder, la idea original siempre fue experimentar y/o probar el uso del cañón arponero, de cuya efectividad para dar cuenta de los abundantes cetáceos habidos en esta parte del globo, dependería la evaluación final de la intentona, ya que nunca estuvo entre los objetivos comprobar la presencia y densidad de los cetáceos, información de suyo conocida. Un comentario de Blanchard bien sirve para ratificar lo aquí comentado, en momentos que le informa a su socio de que a los dos días de zarpar el Magallanes aquel 18 de septiembre, varó una ballena en la bahía de Punta Arenas, lamentándose de que el cetáceo finalmente se haya zafado, perdiéndose [...] una magnifica ocasión de hacer una prueba interesante en la misma bahía ${ }^{69}$. En la misma línea va lo informado por El Comercio, probablemente refiriéndose a la misma ballena varada mencionada por el socio de Braun, cuando relata que aquel 22 de septiembre se le ha escapado al Magallanes lo que habría podido ser la primera víctima de su mortero lanza arpones ${ }^{70}$. Finalmente, tras regresar de la segunda campaña, se informaba que el cañón de que está armado el ballenero ha dado el resultado que se deseaba ${ }^{71}$.

Y desde el punto de vista económico, la inversión más fuerte que requirió este "experimento ballenero", fueron las $£ 3.700$ pagadas para adquirir el Magallanes (originalmente Cabenda), a lo que debe sumarse las $£ 1.000$ por concepto

68 El Magallanes, 5 de diciembre de 1903.

69 Carta de Juan Blanchard a Mauricio Braun, 2 de octubre de 1903, CMB, Volumen 15, f. 85. AMB, Museo Regional de Magallanes [Punta Arenas]. del equipamiento (cañón arponero, arpones, munición y accesorio). Este costo prácticamente se cubriría con el beneficio de los cuatro cetáceos arponeados, hecho que habría sido determinante en la concreción de los deseos de Andresen de involucrarse en propiedad en la industria ballenera moderna, y por cierto también, en la inicial escasa convicción de Mauricio Braun, a la hora de involucrarse en esta actividad. Dos meses después, la prensa local daba a conocer que se le había retirado de cubierta el cañón arponero y que existía el propósito de mandar construir a Noruega un barco que reúna todas las condiciones necesarias para esta clase de pesquería ${ }^{72}$. Lo que siguió es historia ya conocida, que inicia a fines de 1904, cuando se conforma la compañía De Bruyne, Andresen y Cia, origen de la postrer Sociedad Ballenera de Magallanes (Quiroz, 2011, p. 34).

\section{CONCLUSIÓN}

El objetivo de este trabajo fue realizar una reconstrucción del proyecto ideado por el capitán noruego Adolfo Andresen y financiado por Braun \& Blanchard, llegado a Magallanes en 1894, cuya trascendencia está dada por marcar el inicio de toda una cultura ballenera en Magallanes, que luego se extenderá desde la Antártica por el sur, hasta Iquique por el norte. Aquello inició ese doblemente histórico 18 de septiembre de 1903, con el zarpe de la primera campaña, donde en estricto rigor, se habría utilizado por vez primera equipamiento moderno para la caza de cetáceos en Magallanes, Chile y el hemisferio austral, atendiendo a la pequeña ballena en la que se ensayó un primer infructuoso disparo. Será en diciembre de 1903, cuando en efecto, se produce la captura de la primera ballena con aquel equipamiento.

De igual modo, buscábamos caracterizar las dos campañas que conformaron este "experimento ballenero", mezcla de tradición ballenera moderna, expresada en el uso del cañón arponero y de una embarcación a vapor; elementos propios de caza pelágica desarrollada por los balleneros estadounidenses, en este caso específico, lo que

70 El Comercio, 22 de septiembre de 1903.

71 El Comercio, 18 de febrero de 1904.

72 El Comercio, 19 de abril de 1904. 
respecta al modo de procesar a los cetáceos sobre la cubierta de la nave, aunque sin los característicos try works, sino que más bien, con improvisados fondos o pailas, elementos que nos llevan a pensar en una tercera influencia, la que habría llegado por la vía del constante avistamiento y recaladas de veleros dedicados a la caza de lobos marinos, actividad que hacia 1860 comenzó a ser practicada por residentes de Punta Arenas. Esta mixtura permite señalar que el término sui géneris utilizado por Martinic para referirse al vapor Magallanes, aplica también para esta operación ballenera en su totalidad.

El resultado de los cruceros arrojó la cifra de cuatro ballenas beneficiadas, 3.700 lobos faenados, obteniéndose aproximadamente 500 barriles de aceite, además del cuero de los otáridos. A pesar de lo exiguo que pueden parecer las cifras, sirvieron para amortizar el costo del experimento, probar la eficiencia del cañón arponero, y para que finalmente, se decidiera dar inicio a un emprendimiento a mayor escala, que a la sazón perduraría hasta noviembre de 1916, cuando se rematan los últimos bienes de la Sociedad Ballenera de Magallanes.

Finalmente, creemos haber contribuido a conocer algo más de la trayectoria del noruego Adolfo Andresen, quien con el conocimiento previo traído desde su patria, y el adquirido durante las actividades en las que se ocupó al llegar a Magallanes -transportando materiales de construcción y fardos de lana a diferentes establecimientos ganaderos de la Patagonia, así como a la caza de animales pelíferos, como quedó demostrado con el número de otáridos habidos en los cruceros desarrollados entre septiembre de 1903 y febrero de 1904-, vislumbró y ejecutó con éxito el que sería el primero de varios emprendimientos balleneros.

\section{AGRADECIMIENTOS}

Nuestros agradecimientos por las facilidades entregadas por el Museo Regional de Magallanes, para acceder a la colección epistolar del Archivo Mauricio Braun, especialmente por la inestimable disposición de su encargado del Área Educativa, Dusan Martinovic.

Este trabajo fue escrito gracias al financiamiento otorgado al Proyecto 1170318 "Narrativas etnográficas y operaciones balleneras en las costas sudamericanas entre los siglos XVII y XX: patrones, transformaciones y continuidades" por el Fondo de Desarrollo Científico y Tecnológico (FONDECYT).

\section{FUENTES DE CONSULTA}

Primarias

Daily Telegraph (Londres), 17 de septiembre de 1877.

El Magallanes, 1894, 1895, 1896, 1903

El Comercio, 1903-1904

Liverpool Mercury (Liverpool), 14 de julio de 1891.

Lloyd's Register of British and Foreign Shipping. Londres: Wyman \& Sons. 1874.

Correspondencia Mauricio Braun, Volumen 8(1), 14, 15. Archivo Mauricio Braun, Museo Regional de Magallanes, Punta Arenas.

Memoria del Ministerio de Marina presentada al Congreso Nacional en 1897. Santiago: Nacional.

\section{BIBLIOGRAFÍA}

Braun, A. (1985). Mauricio Braun. Memorias de una vida colmada. Buenos Aires: Autoedición.

Brown, S. G. (1976). Modern whaling in Britain and the northeast Atlantic Ocean. Mammal Review, 6(1), 25-36.

Chamorro, C. (1936). Bajo el cielo austral. Tomo I. Santiago: La Ilustración.

Contardi, J. (1920). Ganadería, Industrias y Comercio del Territorio de Magallanes. Punta Arenas: Imprenta Universo.

Davis, L. E., Gallman, R. E., \& Gleiter, K. (1997). In pursuit of Leviathan: Technology, institutions, productivity and profits in american whaling, 1816-1906. Chicago: The University of Chicago Press.

Dickinson, A. (2007). Seal Fisheries on The Falkland Islands and Dependencies: An historical review. Research Maritime History, 34, 39-49.

Filippi, A. (1997). El comodoro Andresen y la ballenería antártica chilena. Revista de Marina, 115(3), 247-257.

Forbath, P. (2002). El río Congo. Descubrimiento, exploración y explotación del río más dramático de la tierra. México: FCE.

Headland, R. (1992). The islands of South Georgia. Cambridge: Cambridge University Press.

Hochschild, A. (1999). King Leopold's Ghost: A Story of Greed, Terror and Heroism in Colonial Africa. Boston: Mariner Books. 
Lynn, M. (2002). Commerce and Economic Change in West Africa: The Palm Oil Trade in the Nineteenth Century. Cambridge: Cambrige University Press.

Martinic, M. (1973). Actividad lobera y ballenera en Magallanes y Antártica, 1868-1916. Revista de Estudios del Pacífico, 7, 7-26.

Martinic, M. (1975). Adolfo Andresen, pionero de la caza ballenera chilena. Boletín Informativo del Instituto Antártico Chileno, 5, 7-13.

Martinic, M. (1977). Antecedentes históricos sobre la caza de cetáceos en Chile. Anales del Instituto de la Patagonia, 8, 313-315.

Martinic, M. (1985). Magallanes de antaño. Punta Arenas: Sociedad Difusora de la Patagonia.

Martinic, M. (1987). Navegantes norteamericanos en aguas de Magallanes durante la primera mitad del siglo XIX. Anales del Instituto de la Patagonia, 17, 11-17.

Martinic, M. (1995). Los armadores de Punta Arenas. 18701930. Revista de Marina, 2(95), 132-142.

Martinic, M. (2001). Ménendez y Braun. Prohombres patagónicos. Punta Arenas: Ediciones de la Universidad de Magallanes.

Martinic, M. (2006a). Historia de la Región Magallánica. Tomo II. Punta Arenas: Ediciones de la Universidad de Magallanes.

Martinic, M. (2006b). Historia de la Región Magallánica. Tomo III. Punta Arenas: Ediciones de la Universidad de Magallanes.

Martinic, M. (2009). Relaciones y Comercio entre Magallanes y las islas Falkland (1845-1950). Magallania, 37(2), 5-21.

Quiroz, D. (2011). La flota de la Sociedad Ballenera de Magallanes. Historias y operaciones en los mares australes (1905-1916). Magallania, 39(1), 33-58.

Quiroz, D. (2012). Cazadores tradicionales de ballenas en las costas de Chile (1850-1950). Santiago: Centro de Documentación de Bienes Patrimoniales. Recuperado de: http://www.cdbp.cl/652/articles-26011_archivo_ 01.pdf

Quiroz, D., \& Carreño, G. (2010). El último sueño del Capitán "Adolfus" Andresen: La caza de ballenas en aguas magallánicas (1933-1935). Magallania, 38(1), 37-60.

Quiroz, D., \& Carreño, G. (2017). Narrativas etnográficas sobre ballenas y balleneros en las costas de Chile. Antipoda. Revista de Antropología y Arqueología, 28, 35-55.

Roldán, J. (2004). 10.000 kilómetros por las rutas de la Argentina. Buenos Aires: Grupo Abierto Comunicaciones.

Royden, E. (1953). Thomas Royden \& Sons, Shipbuilders, Liverpool, 1818-1893. Liverpool: Binding Publishers.

Salvo, L. (2000). Historia de la industria pesquera en la Región del Bío Bío. Santiago: Lom Ediciones.

Stanley, H. M. (1872). How I found Livingstone : Travels, adventures, and discoveries in Central Africa, including four months' residence with Dr. Livingstone. Londres: Sampson Low, Marston \& Co.

Stanley, H. M. (1890). Through the Dark Continent. Londres: Sampson Low, Marston, Searle \& Rivington Ltd.

Starbuck, A. (1876). History of the American Whale Fishery from its Earliest Inception to the Year 1876. Seacaucus: Starbuck.

Tønnesen, J. N., \& Johnsen, A.O. (1982) The History of Modern Whaling. University of California Press: Berkeley and Los Angeles.

Varas, C. (1996). Cien años del Astillero Varadero más austral del mundo. 1896-1996. Valparaíso: Imprenta Victoria.

Véliz, C. (1961). Historia de la Marina Mercante de Chile. Santiago: Ediciones de la Universidad de Chile.

Wakefield, W. H. (1931). A Brief History of Thos. Royden \& Sons. Liverpool: manuscrito.

White, H. (1958). Fossets. A record of two centuries of engineering, Bromborough: Fawcett, Preston \& Co. Ltd. 


\section{ANEXO}

\section{DOCUMENTO 1:}

¿Un casus bellis?

Por la nota que la casa Braun y Blanchard de esta plaza ha dirigido a la Gobernación Marítima y que copiamos a continuación, se impondrán nuestros lectores de un curioso incidente, llamémoslo así, a que ha dado lugar el último viaje del vapor nacional CABENDA al puerto argentino de Santa Cruz. Señor Gobernador Marítimo. Muy señor nuestro. Por la presente participamos a Ud. la llegada a este puerto del vapor CABENDA de nuestra propiedad, de regreso de San Julián y puertos intermedios; por haber tenido en su viaje un incidente, le comunicamos la relación del capitán a ese respecto, que dice lo siguiente: En la noche del 3 a 4 de febrero, a las 5 a.m. fondeábamos en la boca del río Santa Cruz, cerca de Monte Entrance, por encontrar la corriente en contra. Quedamos fondeados en este lugar hasta las 12 del día a pesar de haber cambiado la corriente a las 11 a.m. Concluidos de almorzar y estando virando ancla, avistamos un vapor que resultó ser el 1 DE MAYO. Nosotros entrábamos por el sur de la isla Leones mientras el 1 DE MAYO entraba al norte de dicha isla. De lejos vimos que el 1 DE MAYO nos hacía señales que no pudimos distinguir por encontrarnos demasiado lejos. Entrando ya cerca del Quemado pudimos distinguir las señales que decía "fondee", cosa que no pudimos hacer por encontrarnos en muy poca agua; seguimos por consiguiente nuestro viaje hasta el Quemado y estando al oeste $e$ inmediato a la barca argentina USHUAIA nos pasó el 1 DE MAYO al que saludamos y que contestó nuestro saludo, habiendo arriado ya las señales antes. Habiendo oído decir que el capitán de puerto de Santa Cruz vivía en Pescadores y siguiendo viaje el 1 DE MAYO hasta Misioneros, creímos que se recibirian los buques en Misioneros y fuimos atrás de él. En frente de Misioneros, al dar vuelta con la intención de fondear, el $1 \mathrm{DE}$ MAYO nos hizo otra vez las señales anteriores $y$ antes de encontrarnos en un lugar apto para fondear, descargó una salva de rifle sobre el buque, cayendo las balas alrededor de éste, felizmente sin causar daño, ni herir gente. Una vez fondeados pasó el 1 DE MAYO al costado nuestro y preguntó de dónde veníamos, a lo cual se contestó, de Gallegos. El tiempo de ver las señales de nuevo en el 1 DE MAYO y la descarga ha sido de 5 a 10 minutos. Lo que comunicamos a Ud. para los fines a que haya lugar. De Ud. muy atto. y S. S. Braun y Blanchard. ¿No será del caso suponer que el Sr. Comandante del 1 DE MAYO ha querido parodiar el primer episodio de esa fantástica guerra forjada por la brillante imaginación de un general argentino y cuya relación en la prensa de Buenos Aires ha despertado tanto interés en ese ambiente suspicaz de ultra cordillera?

El Magallanes, 24 de febrero de 1895.

\section{DOCUMENTO 2:}

[...] Nuestros vecinos están verdaderamente afectados de la monomanía del espionaje. En las costas del Sud. Un buque misterioso.

Recibimos por conducto fidedigno, detalles de un hecho cuya aclaración se impone y ante el cual está el gobierno en el deber de abandonar su apático proceder y tomar medidas que corten de una vez por todas los abusos que bajo el amparo de la bandera chilena o por agentes de aquella nación, se vienen cometiendo de mucho tiempo atrás. Por hoy nos limitaremos a narrar los hechos sin entrar en comentarios, esperando la acción de nuestras autoridades. El 4 del presente, un vapor con bandera chilena recorría las costas del sud, frente a la desembocadura del río Santa Cruz, sin que sus maniobras demostraran intención de tomar puerto; el día 5 reapareció, penetrando decididamente en dicho río, recorriendo cuidadosamente el canal hasta frente a la punta de la isla de Los Leones, a unas dos leguas del presidio militar, donde permaneció un momento estacionado, luego viró y emprendió una rápida retirada. 
Pero en ese momento penetraba por el mismo canal el transporte nacional 1 DE MAYO. Visto lo cual el trasporte argentino le hizo señas ordenándole ponerse al habla y seguirlo al puerto, no quedando al vapor chileno otro arbitrio que acatar la intimación. Al enfrentar el presidio militar el 1 DE MAYO varó, por lo cual ordenó al otro vapor que fondeara, pero éste, lejos de obedecer la orden, y aprovechando este accidente, viró y emprendió la fuga, por lo cual el transporte rompió contra él un fuego de fusilería que le obligó a detener la marcha y como en Aquel momento zafara de su varadura, se aproximó al vapor chileno, del cual se desprendió una lancha con algunos tripulantes que se trasbordaron al 1 DE MAYO. Las explicaciones que mediaron se ignoran y aunque lo sospechoso de las maniobras efectuadas por el chileno imponían una revisión a bordo, no se efectuó. Datos recibidos dan a comprender que el proceder del comandante del transporte ha dejado mucho que desear. Es por esto que antes decimos se imponen una aclaración de lo sucedido y la comprobación de haber el jefe argentino cumplido fielmente su deber, probando plenamente no haber causa contra el buque chileno, lo cual es dudoso, según los informes de personas que desde la costa siguieron todos sus movimientos. Debemos agregar que el gobernador del presidio militar, a pesar de tener a sus órdenes una compañía de línea, no tomó aquellas medidas que en este caso se imponían. ¿De qué se trata? ¿Han cesado los espionajes por tierra para dar principio por mar? ¿Bajo el pabellón chileno vienen buques a piratear en nuestras costas, como antes los salvajes robaban en nuestros campos? La explicación de estos hechos tiene derecho el pueblo a pedirla y es por esto que esperamos la palabra del ministro de guerra y marina, quién está en el deber de tener al respecto los mayores datos que nosotros.

El Magallanes, 7 de abril de 1895.

\section{DOCUMENTO 3:}

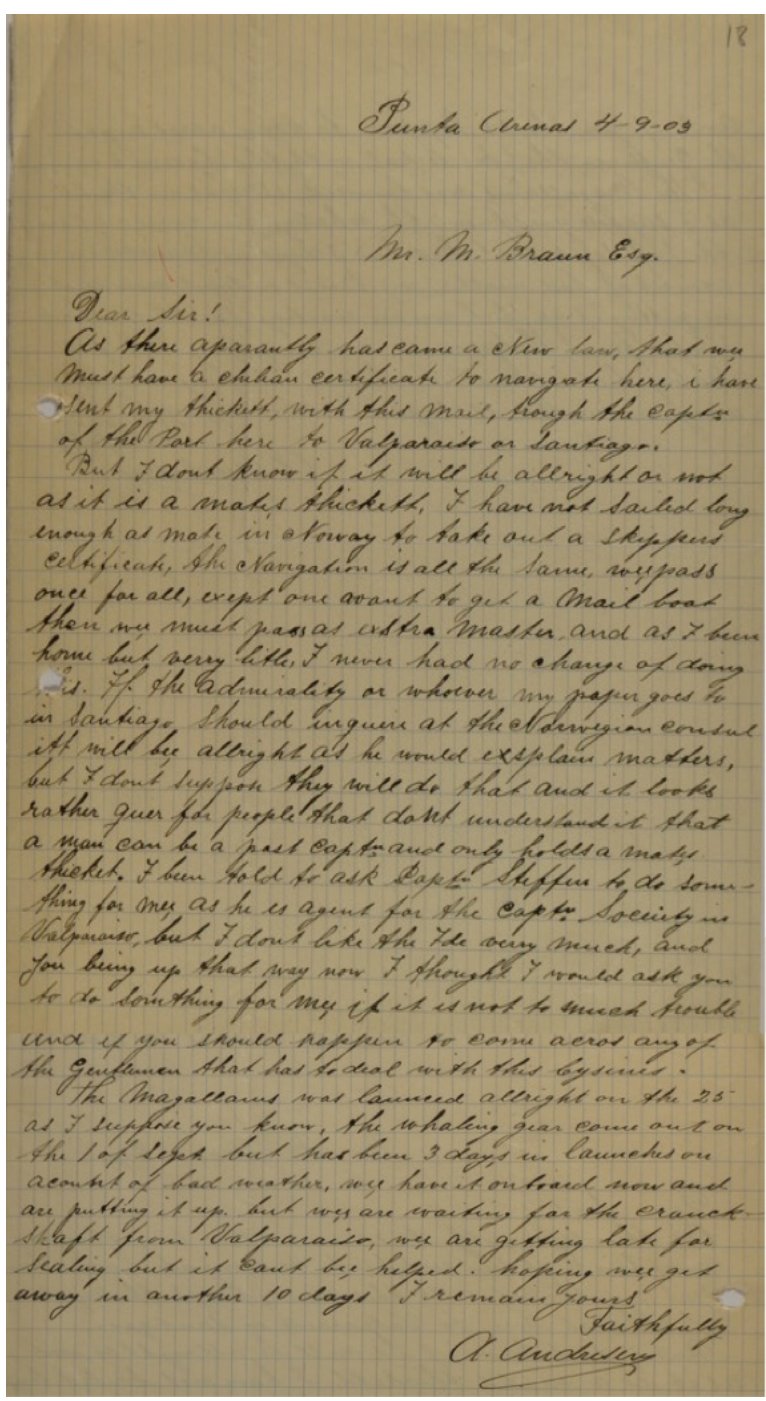

Punta Arenas 4 - 9 - 03

M. M. Braun Esq.

Estimado señor!

Puesto que aparentemente ha aparecido una nueva ley, que debemos tener un certificado chileno para navegar aquí, he enviado mi carnet, con este correo, a través del capitán del puerto de aquí hacia Valparaíso o Santiago.

Pero no sé si estará bien o no, ya que es un carnet de primer oficial. No he navegado lo suficiente como primer oficial en Noruega como para obtener un certificado de capitán, la 
navegación es la misma, todos lo hemos pasado alguna vez, excepto respecto de los paquebotes donde se debe poseer un carné extra de patrón de nave, y dado que he estado en casa pero muy poco, nunca tuve la chance de hacerlo. Si el Almirantazgo o quien sea que lleve mi papel a Santiago, podría preguntar al cónsul noruego si es el correcto o si pudiera explicarle sobre el tema, pero no creo que lo hagan y parece más bien una pregunta para las personas que no entienden que un hombre pudo antes ser un capitán y poseer solamente el carnet de primer oficial. Me han dicho que le pregunte al Capitán Steffen que haga algo por mí. ya que él es agente de la Sociedad de Capitanes en Valparaíso, pero no me gusta mucho la idea, y si usted está haciendo lo mismo ahora, pensé que le pudiera preguntar si puede hacer algo por mi si acaso no es mucho problema y si es fuera posible acudir a cualquiera de los caballeros que tengan que ver con este asunto.

El Magallanes fue botado correctamente el 25 , como supongo que usted sabe, el equipamiento para cazar ballenas salió el 1 de septiembre pero se ha estado 3 días en maniobras producto de mal tiempo, ahora lo tenemos a bordo y lo estamos instalando, sin embargo, estamos esperando que llegue desde Valparaíso el eje de la hélice, de modo que se está haciendo tarde para fijarlo, en fin no podemos evitarlo Espero que podamos zarpar en 10 días más. A su disposición.

Atentamente

A. Andresen 